\title{
ERAKUSTEN, BIZITZEN IKASTEN
}

\author{
Imanol Esperesate Azpiazu \\ Universidad del País Vasco / Euskal Herriko Unibertsitatea. Eskultura eta Artea eta Teknologia \\ Saila. Eusko Jaurlaritza HUISeko ikertzaileen prestakuntzarako programaren doktoretza-aurreko \\ bekaduna. \\ GIC IT1096/16-21 Ikerketa Taldea ${ }^{1}$
}

\section{Laburpena}

Helduleku eta pausalekuen inguruan, gorputzen eta gauzen arteko hartu-eman eta joan-etorrian, mugimendua eta pausaldia tartekatzen dira. Helduleku zein pausalekuek besteari erreparatzen diote, heltzen eta pausatzen denari, hori gertatzen den lekua baitira. "Heldu" edo "heltzen" eta "pausatu" edo "pausatzen" aditzak dira, aditz-partizipioa (infinitiboa) eta aditz-izena (gerundioa), hurrenez hurren. Aditzak topaguneetan hezurmamitzen, abstrakziotik lurreratzen dira. Topaguneak arkitekturan materialen eta loturen gordintasuna hainbat eratara erakusten duten eraikuntza xehetasun gisa azaltzen zaizkigu. Juhani Pallasmaak (Merleau-Pontyren pentsamenduak eraginda) arkitekturan "espazio" eta "denbora" bezalako izenek gertaeretan oinarritzen den bizipena desitxuratzen dutela dio. Topagune edo xehetasunak "beren horretan" erakusteko eta aditzaren izaera azaleratzeko saiakera ugari egin dira artean eta arkitekturan. Testu honetan, arkitektura irakastetik erakustera eta erakustetik bizitzera igarotzen den Alison eta Peter Smithson eta Sigurd Lewerentz arkitektoen hainbat lan erlazionatzen dira; gorputza xehetasunaren partaide egiten dutenak, gorputzak xehetasuna osatzen buka dezan.

\section{Gako-hitzak: HELDULEKUA; PAUSALEKUA; GORPUTZA; TOPAGUNE/ XEHETASUNA; ADITZA}

\section{SHOWING, LIVING AS LEARNING}

\begin{abstract}
All around the handle and the resting place and the exchange and the to-ing and fro-ing between bodies and things, movement and rest are combined. Both the handle and the resting place refer to the other, what is hanging and resting, as they both are the place to do so. "to hang" or "to be hanging" and "to rest" or "to be resting" are verbs, the infinitive and gerund, respectively. Verbs are shaped throughout the joint, they land from their abstraction. In architecture, the joint is characterized by the building details where the rawness of the materials and joints can be shown in many ways. Juhani Pallasmaa (influenced by Merleau-Ponty's thought) claims that nouns like "space" and "time" have distorted the living experiences in architecture. Many attempts have been made to show these joints or details "as found" as well as to emerge the action of the verb both in art and architecture. In this text, some works by the architects Alison and Peter Smithson and Sigurd Lewerentz will be listed, in which architecture can be shown instead of taught, can be lived instead of shown; attempts that make the body part of the detail or situation so that they can finish off it.
\end{abstract}

Keywords: HANDLE; RESTING PLACE; BODY; JOINT/DETAIL; VERB

\footnotetext{
Esperesate Azpiazu, Imano1. 2020. "Erakusten, bizitzen ikasten”. AusArt 8 (2): 77-87. DOI: 10.1387/ausart.22030
}

\section{AUSART}




\section{HELDULEKU ETA PAUSALEKUEN ARTEAN}

Hel nazazu gerritik lagun zaitzadan.

Helduleku eta pausalekuen artean bizi gara, mugimenduan eta geldiunean. Gorputzek bizitzeko helduleku eta pausalekuen beharra dute. Biek besteari, gorputz edo gauzari, erreparatzen diote, helduko dutenari eta pausatuko denari. Gorputza eta gauza maiz nahastu egiten dira elkarren artean, batzuetan zaila da zehazten noiz hasten eta noiz bukatzen den bakoitza. Bereizezinak dira, maiz, heltzeko edo pausatzeko prest dagoena eta horretarako espresuki atondutako bermea: lekua. Hain bereizezinak biak, ezen bata bestearengandik banatzean elkarri zerbait erauzten baitiote, bakoitzak aldean bestearen zerbait eramanez, batasunaren eta bereizketaren arrasto. Biek ere lekuari erreparatzen diote, lekuan lekutzen ${ }^{2}$ dira, lekuan gorpuzten. Heldulekua zein pausalekua helduko dutenaren eta pausatuko denaren aurretik daudenez, halabeharrez baldintzatzen dute gonbidatu edo iritsi berria . Biek hartu-eman eta joan-etorriei leku egiten diete.

Heldulekuak bere egiten du heltzen duen hori, eskua, esaterako. Lekuaren nolakotasunak (heldulekuak berak) baldintzatuko du heltzeko era. Atearen helduleku edo kisketatik abiatu gintezke eta eskudel edo eskubandarekin jarraitu arrapalan edo eskaileretan gora eta behera. Hauek eskuaren neurrira eginda daude, esku-ahurrean ahokatzen dira. Ukimen bidezko lotura xeheak dira, bat egitea eta bereiztea, oro har, errazteko beren-beregi sortu direnak. Eraikin baten sarrerako atearen heldulekua besteen gainetik nabarmendu daiteke, eraikinaren luzapena den eta sarrera atari egiten parte hartzen duelako. Juhanni Pallasmaa eta Peter Zumthor arkitektoek zinez heltzen diete helduleku horiei. Pallasmaak "atearen heldulekua eraikinaren bostekoa" dela dio, "erakargarria eta adeitsua izan daitekeena, edo zakar eta oldarkorra" ([1996] 2006, 68-9). Zumthorrek haurtzaroko oroitzapen iraunkor baten baitan kokatzen du izebaren jardineko atearen heldulekua: "Batzuetan, oraindik, senti dezaket nire esku ahurrean atearen helduleku hura, koilararen atzealdearen forma duen metal zatia. Nire izebaren jardinean sartzen nintzenean heltzen nuena. Atearen helduleku hura, aldarte eta usain askotariko mundu baten sarreraren ikur berezia dela iruditzen zait oraino" (Zumthor [1998] 2014, 7). Ate batzuek ez dute heldulekurik, sarrailan sartzen den giltzak betetzen du funtzio hori. Askok heldulekua dute, baina, atea irekitzeko orduan bazter uzteko apaindura gisa bakarrik; eraikinetik irtetean atea ixten laguntzeko akaso. Alison eta Peter Smithson arkitektoen asteburuak eta oporraldiak pasatzeko Upper Lawn etxeko (Tisbury, 1959-62-82) aluminiozko ateak kanpotik ez du heldulekurik. 
Atea ixtean ateratzen zuen danbateko hotzaz oroitzen da egun Simon Smithson, arkitektoen semea ${ }^{3}$.

Richard Sennett soziologo eta musikariak heltzeko ekintza, alegia, oratzea, borondatezko ekintza gisa aurkezten du, erabaki batetik datorrena, begien kliskatzearekin (ez ixtearekin) gertatzen ez den bezala ([1997] 2009, 100). Sennettek objektu bat oratzeko ekintzak aurretiko prestakuntza, mugimendua, hots, objekturako gerturatzea bere egiten duela gaineratzen du (102-3). Izan ere, oratzeko ekintzak, edalontzi bat oratzeko prestatzen dugun esku-ahurraren eta edalontzia eskuratzen dugunaren arteko tartea betetzen du. Zerbait heltzeko keinuak aurreukitu edo aurrez ukitu dezakeen seinale. Aurreikuspenetik aldenduko litzateke, begiekin ezin baita ikusi besterik, aurrez ikusteko beste elementu batzuek parte hartzen dutelako. Aurreukitzeak gertatzen ari denaren edo gertatzear dagoenaren alde egiten du, gertatzen ari denari gertatzen uzteko. Aurreikuspenak, aldiz, gertatzen ari dena baztertu dezake eta gertatuko dena baldintzatu edo behartu, hau da, sortu. Sennettek heldutakoa askatzeko gaitasunean ere jartzen du arreta, oratzearen ezinbesteko atal baita, heltzea bezain borondatezkoa (101).

Pausalekuak pausatzeko leku bat eskaintzen du. Hein handi batean egonkorra behar du izan, azalera lau antzeko bat, makurregia ez dena, sendoa. Pausatzeko ekintza denboran zehar luzatzen da, eten bat izan daiteke, geldialdi bat, gerturatzeko mugimenduaren eta gerturatzen jarraitzekoaren artean. Gorputza bere osotasunean orpoen gainean pausatzen da. Orpoa gorputzaren azken luzapena da pausalekurik oinarrizkoena den lurzoruarekin topo egin aurretik. Eskuek ere pausatze hori egonkortzen lagun dezakete, horma baten gainazalean, petrilaren karelean, leihoaren barlasaian pausa baitaitezke. Pausalekuak lurzoruari gainjartzen zaizkion geruzak dira, bai berarekin kontaktuan bai bereizita. Lurzoru berri bat sortzen dugunean, oinarrizkoena imitatzen dugu, oinarrizkora egokitzen gara: bere egonkortasun, segurtasun eta erreferentzialtasuna. Lurzorutik bereizi gintezke bertan bermatzen edo sartzen den eskuko eskailera batekin. Eskuko eskailera gorputzaren luzapen gisa: esku zein orpoa eskailera mailetan gora eta behera. Belaunetara iristen den enbor moztu batekin ere bereiz gintezke, eta aldendu ere bai, bereizi gabe, muino batean gora.

Heldu eta pausatu; hartu eta eman; joan eta etorri. Bikote horien artean txertatu genitzake gorputza eta gauza eta horien bueltan eraiki paisaia. Aditzek gertaerak ahoskatzen, lekutzen eta gorpuzten dituzte. Aditzak heldulekuen eta pausalekuen beharraz mintzo zaizkigu eta horien arteko topaguneetan hezurmamitzen, abstrakziotik lurreratzen dira. Topaguneak gorputzen artean, 
gorputz eta gauzen artean, topaguneak gauzen artean. Topaguneak arkitekturan eraikuntza xehetasun bezala azaltzen zaizkigu. Peter Zumthor arkitektoa izateaz gain, zurgina ere bada, zeinak bere arkitekturan eragin zuzena duen:

Arkitektoek egindako marrazki guztien artean, nire gustukoenak eraikuntza planoak dira. Eraikuntza planoak xehetasunez beterik daude eta objektiboak dira. Eraikuntza planoak, pentsatutako objektuari materiadun forma emateaz arduratzen diren artisauei zuzentzen zaizkie eta erakutsia izateak dakarren manipulazio orotik aske daude. Ez dute proiektuko marrazkiek bezala, konbentzitu edo zirrara eragin nahi. "Hau da zehazki izango dena" esaten ari direla dirudi. Eraikuntza planoak anatomia planoen gisakoak dira. Ezkutuko barne tentsioen berri ematen dute, arkitektura-gorputz bukatuek nekez egiten dutena: mihiztatzea, geometria ezkutuak, materialen marruskadura, euskarri- elementuen eta euskarri-loturen barne-indarrak eta eskuz egindako lanak berezkoa duen giza-lana.

(Zumthor [1998] 2014, 18)

"Hau da zehazki izango dena" dio Zumthorrek, hori da eraikuntza plano baten funtsa, eraikuntza lanak nolabait aurreratu eta planoan marraztu bezala eraikitzea. Zurezko eraikuntza-elementuen arteko lotura edo mihiztadura ugari ahokatzean oinarritzen diren aho-zirika eta miru-buztan (bi nagusi aipatzearren) bidez eraiki izan dira. Kanpoko sinpletasun eta jarraitutasuna barruko eta ezkutuko lotura ia ezinezko eta benetan konplexuei esker lortzen dira, zeintzuek elementuen arteko hartu-emana perfekziora eramaten duten. Oro har, itsasgarririk erabiltzen ez dutenez, atzeragarriak dira, eraiki bezala deseraiki daitezke, bat egin diren bezala bereizi. Batzuetan beharrezkoa da hirugarren elementu baten beharra, adibidez, ziriarena: bi elementuak zeharkatzen ditu, bai alderik alde bai muturrak arinki janez. Xehetasun horietan zurari gorazarre egiten zaio, zura "bere horretan", gordinki, azaltzen baitzaigu. Japoniarren mihiztadurek ez dute xehetasuna nola eraikita dagoen erakusten, kanpotik bata bestearen gainean bermatuta, ondoan kokatuta daudela dirudi. Kanpoko sinpletasunaren alde barruko konplexutasuna ezkutatzen dute, xehetasun horien marrazketa planoek konplexutasun hori azaleratzen duten bitartean. Gordintasun mota desberdinak daude, materialak "beren horretan" erakusteko hamaika modu. Gordintasuna dotorea, leuna izan daiteke, Japoniarren mihiztaduretan edo Miesen arkitekturan bezala: materialen alde beti, ez dute guztia bistaratuko. Gordintasuna ere lakarra izan daiteke, inperfekzioa onartzen eta material edo elementu bakoitza non hasi eta non bukatzen den bistaratzen duena: barru zein azal parekide. Topagune batzuk pausaldian daude, beste 
batzuek pausaldia eta mugimendua tartekatzen dituzte eta batzuk mugimendu etengabean xehetzen dira.

\section{URAREN BIDETIK IKASTEN}

Urak bere bidea egiten du ezkutuan zein bistan. Plaza eta kaleetan euri-urak nola hustubidera lerratzen diren ikustera ohituta gaude; estalkietako ura, erreten eta zorrotenetan behera nola lurzorura erortzen den ikusi izan dugu inoiz, imajinatu dezakegu metalezko edo plastikozko hodietan barrena. Eraikin barruan ura txorrotatik irteten eta harraskan edo konketan behera ihes egiten ikustera ere ohituta gaude. Horma, zoru zein sabaiek ezkutatzen dute bere bidea. Alison eta Peter Smithsonek Louis Kahn aipatzen dute sabai faltsua ez dela ezertaz mintzo adierazteko: ez da ezkutatzen dituen zerbitzuez mintzo, ezta ezkutatzen duen gaineko egituraz ere, azpiko espazioaz ezta ere. Sabai faltsua zerbaitez mintzo bada eraiki duten eskuez mintzo da (Smithson \& Smithson 1973, 48). Smithsondarrek Hunstantoneko Bigarren Hezkuntzako Eskola Modernoko (1949-54) komunetan uraren bidea bistaratzen dute. Instalazio hodiak bistan daude eta konketetatik ura tapakirik gabeko zoruko erretenera zuzenean erortzen da. Hunstantonekoa gerraosteko eskola bat da, 1944ko Butler Education Act hezkuntza lege aitzindariari erantzuten diona. Legeak ekarri zituen berrikuntzen artean daude, besteak beste, bigarren hezkuntza doako baten eskaintza eta bigarren hezkuntza adinari, gaitasunari eta jarrerari egokitutako hiru eskola desberdinetan banatzea: institutua (ingelesez 'grammar school'), maila intelektual baxuagoko bigarren eskola modernoa (Hunstantoneko Eskola kasu) eta eskola teknikoak. Ez zen harritzekoa, beraz, Hunstantonen, oinarrizko curriculumaren bueltan, zurgintza, sukaldaritza eta metal langintza bezalako bereziki eskuzko irakasgaiak lantzea. Uraren bidea bertatik bertara ikustea ere irakasgai bat izan zitekeen, erakutsiz irakasteko era bat; baita habearteetan dauden leiho-gurutzeek beirazko xaflak nola eusten dituzten ikustea ere, edo habearte handi eta ireki bat eusten duen zertxa baten azpitik igarotzea, sarreran eta gimnasioan gertatzen den bezala.

Urari bidea errazten eta erakusten dion beste arkitekto bat Sigurd Lewerentz dugu. Klippango San Petro elizako (1963-1966) komunetan konketetako ura ez da ohiko iturri batetik iristen: kanpotik datozen ur hotz eta beroaren hodi bertikalak altuera jakin batean bateratzen dira eta hormari atxikitako beste hodi batek ura konketara bideratzen du. Hunstantonen ez bezala, uraren etorria 
azaleratzen du Lewerentzek, ur zikinen hustubidea zoruan ezkutatzen duen bitartean. Bjorkhagengo San Marko elizan (1956-1960), euri-urak bideratu eta kanporatzeko keinua azpimarratu egiten du, Smithsondarrek zoruko estali gabeko hustubidearekin egiten dutena, leihoen metalezko barlasaian ildaxka antzeko bat moldeatzen duenean urari bidea erraztu eta erakusteko. Uraz aparte, beste xehetasun batzuetan ere, irekiduretan kasu, Lewerentzek azpimarratu egiten du materialen arteko hartu-eman iraunkorra. Beiraren erabilera gordinak leihoak zulo bihurtzen ditu. Metalezko marko fina duten beirazko xaflak itxituran txertatzen ditu, adreiluaren kasuan ertzera eramanez, hormigoiaren kasuan, bertan egindako ildaxkan sartuz. Bietan altzairuzko helduleku batzuek, zeintzuek zerbait heltzean eskuko atzamarrek egindako keinua jarraitzen duten, beira hormara eusten dute eta silikonak beiraren metalezko markoaren eta adreilu zein hormigoiaren arteko zirrikituak ixten ditu (Ahlin 1987).

\section{TOPAGUNE ETA ADITZEN BUELTAN}

Topagune bakoitzak zer gertatzen ari den eta nola gertatzen ari den galderei erantzuten die: bermatzen da eta nola bermatzen da, erortzen da eta nola erortzen, bideratzen da eta nola bideratzen, etab. Xehetasun horiek nolakotasuna diren neurrian, osotasun baten parte dira eta eskua luza diezaiokete gerturatzen zaien gorputzari, gerritik heldu eta partaide egin. Xehetasun xehetik aldenduko ginateke orduan eta esperientzia eta bizipen bidezko beste xehetasun fenomeniko batera lekualdatu. Juhani Pallasmaak, Fred Thompson aipatuz, esperientzia arkitektonikoak izenen ordez aditzen bidez deskribatu behar direla dio, esperientziak une eta leku jakin batean gertatzen direlako; ez dira abstraktuak, lurtarrak baizik. Pallasmaak aditzaren aldeko hautua egiten du izenek desitxuratzen duten bizipen bidezko esperientzia arkitektonikoaren muinera jotzeko:

Mugimendu modernoaren teoria eta kritikak espazioa gainazal materialek definitutako objektu immaterial gisa ulertzeko joera erakutsi dute, espazioa eragin-truke gisa ulertu beharrean. Hala ere, pentsamendu japoniarra espazioaren erlazio bidezko ulermenean oinarritzen da. Esperientzia arkitektonikoaren aditz izaera aitortu nahian, Fred Thompson irakasleak "espazioa" ekintza gisa aurkezten du "espazioan kokatu, espazioa kokatu", eta "denbora iragan" erabiltzen "denbora" beharrean, pentsamendu japoniarrean, Ma 
kontzeptuari eta espazioaren eta denboraren batasunari buruzko saiakera batean. Thompsonek esperientzia arkitektonikoaren unitateak infinitiboekin egoki deskribatzen ditu, izenekin beharrean.

(Pallasmaa [1996] 2006, 76)

Merleau-Pontyk espazio eta denborari heltzen die, baina gorputzak biak bizi dituela zehazten du eta baztertu gorputza espazioan eta denboran dagoela ([1945] 1997, 156). Pallasmaak arkitekturaren izaera fenomenikoa elementu guztietara eramaten du, izenak gainditu eta gorputzari leku egiteko. Leihoa eta atea irekidurak dira berarentzat, marko eta orrietatik haratago, gorputzari bertan pausatu eta geldirik zein mugimenduan zeharkatzera dei egiten diotenak (Pallasmaa 2018, 79).

Heldu, pausatu, hartu, eman, zapaldu, bermatu, lur hartu, lurperatu, eskuratu, besarkatu, gerturatu, gelditu, inguratu, topatu, urrundu, makurtu, belaunikatu, etzan, altxatu, azaleratu, lekualdatu, etab. Gorpuztu eta lekutu. Guztiak aditzak dira, izena borobiltzen, egoera jakin batera egokitzen dutenak. Izena aurreikuspen bat da, ez aurretiko egoera bat. Heldulekua eta pausalekua, biak izenak dira, baina heltzetik eta pausatzetik zuzenean eratortzen direnak. Aditza osatzen eta inguratzen duten izenak dira, aditza, ezabatu ordez, doitzen dutenak. Aditzak gorputzaren eta gauzen arteko zubi-lana egiten du, bai gorputza bai gauza ordezkatuz; lekualdaketa edo eskutik eskurako igarotze bat ahoskatzen du. Mugimendua eta pausaldia ahoskatzen ditu. Izena orokorkerian eror daiteke. Aditza xehetasunetik abiatzen da, bere horretan orokortasuna osatzen duen xehetasunetik. Izenak gertatuko dena aurreikusiko eta gertaeraren gainetik jarriko luke. Aditzak gertaera gertatzear utziko luke, gertatzeko. "Bere horretan" dena ahoskatzen dute aditzek, ez besterik. Biluzik azaltzen zaizkigu.

Richard Serraren To Lift (19674) lana bere kasa zutik eusten den goma bulkanizatu baten tolestura bat da. Serrak gauzak prozesu eta ekintza hutsera mugatu nahi zituen. Horregatik Verblist (1967-19685) aditz zerrenda. Horien artean dago lan honi dagokion to lift (altxatu) aditza:

[Aditz] horrekin topo egin nuen bulkanizaturiko goma zati hau erdigunetik altxatu eta bere kasa eutsi zenean. Zutik mantentzeaz gain gainazala topologiari dagokionean ia jarraitua ere bazen. Eta orduan pentsatu nuen, 'Ez al da bitxia? Egin dudan gauza bakarra aditz baten ekintza jarraitzea izan da, gauza altxatzea.

(Richard Serra, MOMA web-orrian) 
"Altxatu" aditza: aditz baten ekintza jarraitzea leku eta momentu jakinean material batekin zerbait sortzeko. Aipatu aditz zerrendan Serrak, bere hitzez baliatuz, "norberaz, material, leku eta prozesuaz ari diren ekintzak" bildu zituen. Arestian zerrendaturiko aditzak errepikatuko ditugu: Heltzen, pausatzen, hartzen, ematen, zapaltzen, bermatzen, lur hartzen, lurperatzen, eskuratzen, besarkatzen, gerturatzen, gelditzen, inguratzen, topatzen, urruntzen, makurtzen, belaunikatzen, etzaten, altxatzen, azaleratzen, lekualdatzen, etab. Gorpuzten eta lekutzen. Zer eta nola gertatu da? Zer eta nola gertatzen (ari) da?

Aditz-partizipioa eta aditz-izena zer diren azaldu beharrean gaude, gainetik bada ere, euskaran, hurrenez hurren, infinitiboaren eta gerundioaren parekideak baitira. Aditz-partizipioak bi multzotan banatzen dira. Alde batetik, bokalez edo kontsonantez amaitzen diren euskal aditz zaharrak daude, "etorri", "eman", kasu. Bestetik, -tu/-du atzizkiaz osatzen direnak, "heldu", "pausatu", "gerturatu". Aditz-izenak aditzoinari -t(z)e erantsiz lortzen dira eta - $n$ letraz (inesibo mugagabean) amaitzen, "heltzen", "pausatzen" eta "gerturatzen", esaterako. Esan genezake aditzoin bera partekatzen dutela bai aditz-partizipioak bai aditz-izenak, hots, aditzak ez duela esanahia aldatzen batean zein bestean. Gaira bueltatuz, egiturak halabeharrez eragiten dio esanahiari. Lehenengoa gertatu denaz mintzo da, bukatuta balego bezala, edo agindu bezain laster bukatuko balitz bezala. Agindua izenarekin aldera genezake. Bigarrena, aldiz, oraindik gertatu ez denaz, gertatzear eta gertatzen ari denaz mintzo da eta "zertan" galderari erantzuten dio.

Serraren aditzen zerrendako gehienak aditz-partizipio eran azaltzen zaizkigu. Beste batzuk izenetik eratortzen dira eta gutxi batzuk aditz-izenetik. Izenetik eratorri baino ekintza egiten duenari erreparatzen diotela zehaztu beharko litzateke, artistaren gorputzari, horregatik, euskarara "dena/duena" bezala itzul genitzake. Beraz, ondoriozta genezake, aditz-partizipioa bi eratara uler daitekeela: aurreikuspen gisa, gertaera bukatu gabe egon arren bukatutzat jotzen duen neurrian, arestian aipatutako izenera gerturatuz; ekintza jakin baten bukaera gisa, topagune batean kasu, "ziria ahoan edo iltzea oholean sartu dugu" diogunean.

\section{ATARIAN BARRENA IKASTEN}

Gorputzaren zerbitzura helduleku eta pausalekuak eskaintzean datza arkitektura, gorputz bakoitzak bere bidea egin dezan. Bizi ahala, etengabe gorputza 
jarriz, neurtzen du ingurua gorputzak. Egoera edo zirkunstantziaren xehetasuna osatzen duen atal garrantzitsu bat da, gertatzear dagoena bere esku baitago neurri handi batean.

Heldulekua eta pausalekua elkarrekin teilakatu daitezke, are gehiago, leku beraren baitan tolestu, atarian gertatzen den bezalaxe: egoerak egoera, biek bat egin, heltzear eta pausatzear dagoen eta mugimendua eta pausaldia ahalbidetzen dituen lekua. Ataria leku ororen adibidetzat har genezake, ataria zeharkatzen dugun bitartean ikas dezakegulako arkitekturaz. Alison eta Peter Smithsonek horixe bera gertarazi nahi izan zuten Batheko Unibertsitateko Arkitektura eta Eraikuntza Ingeniaritza Eskolan (1984-1988). Arkitektura ikaslea Hunstantoneko Eskolako ikasle xaloagoarekin alderatuta, helduagoa zen bertan. Hunstantoneko Eskolako espazio ireki, garden eta zabalak, ñabardurez jositako espazioek ordezkatzen dituzte Bathen eta inguruko paisaia nahigabe sartzen uzten duten beirate handiak, tarteka irekitzen diren eta paisaia kokatzen duten leiho txikiagoek. Bathekoa, eraikinera sarrerak eta korridoreen arteko bidegurutzeak atari bihurtzeko saiakera bat da, eskailera edo arrapala bidezko kota aldaketa txikiekin, hormen lerrokaduren angelu desberdinekin, korridorearen eta atearen arteko tartearekin... Irakastetik erakustera eta erakustetik bizitzera igarotzeko saiakera bat.

Joan-etorri eta hartu-eman handiko leku bat izan daiteke ataria, non gorputzak sartzen, irteten, gelditzen diren. Urari bidea errazten eta erakusten zaion bezala, erraztu eta erakutsi liezaioke bidea arrapala batek gorputzari. Ez beti erraztu, zaildu ere egin liezaioke eta, hala ere, erakusten jarraitu.

Alison eta Peter Smithsonen Upper Lawn etxeko ataria eta Sigurd Lewerentzen Malmöko Ekialdeko Kanposantuko Lore kioskoko (1968-1969) atzeko ataria elkarren ondoan jarriko ditugu. Bietan eraikinera sartzeko igo beharra dago, bikietara iristen den maila batek bereizten baititu lurzorutik. Smithsondarrek altuera hori arintzen dute ingurutik hartzen eta atearen aurrean pausatzen duten harriarekin. Harriak ataria borobiltzen du. Harriaren aurrean, zirkulu erdi bat marratu eta betetzen dute lurrean sartzen dituzten errekarriekin. Harri borobilduekin borobiltzen bukatzen dute ataria. Lewerentzek, aldiz, bere horretan uzten du lurzoruaren eta atearen arteko tartea eta gorputzari esfortzu handiagoa eskatzen dio (ozenago dei egiten dio) eraikinera sar dadin. Gorputzak berak ordezkatzen du tarteko maila edo harri hori. Ez da lehenengo aldia Lewerentzek gorputza, materialekin egiten duen bezala, amildegiaren ertzera eramaten duena. Aipatu San Petri elizan, bataiarria adreiluzko zoru uhinduan sartzen du eta ur bedeinkatuz bekokia igurtzi nahi duena, putzu batean bezala, 
makurtzera, akaso, belaunikatzera behartzen du, gorputzak xehetasuna xehetzen, osatzen buka dezan.

\section{ERAKUSTEN, BIZITZEN IKASTEN}

Irakastetik erakustera igarotzen den arkitekturak etengabe ikasten ari den gorputza partaide egiten du. Makurtzen eta belaunikatzen gara eta ura bekokian igurzten dugu; txorrota irekitzen eta hustubidean barrena nola bideratzen eta kanporatzen den ikusten dugu; oharkabean sartzen den paisaiaz baliatzen gara dena delakoa egiten jarraitzeko edo, han-hemenka irekitzen diren leihoetatik zelatatzen dugu, dena delako horretaz, une batez bada ere, libratzeko.

Egoera guztiak diren bezala azaltzen zaizkigu. Dena, ez denaren oihartzuna ere bada, oihartzun onartua. Direna azpimarratzen, seinalatzen, erakusten digute; poliki-poliki, ahalik eta ondoen ahoskatuz hitz egingo balute bezala, haurrak bere izena idazten duen bezala... hizki borobildu bakoitza, bata bestearen atzetik, idatzi ahala xuxurlatzen duela... Guztiak izan daitezkeenari ahur, gu (garen bezala) noiz gerturatuko zain, helduleku eta pausaleku guztiak prest dituztela. Partaide egiten gaituzten neurrian, heldulekuei heltzen diegu eta pausalekuetan pausatzen gara; bizitzen ikasten dugu, gu ere izan gaitezkeenari ahur.

\section{Erreferentzia bibliografikoak}

Ahlin, Janne. 1987. Sigurd Lewerentz, architect: 1885-1975. Stockholm: Byggförlaget

Merleau-Ponty, Maurice. (1945) 1997. Fenomenología de la percepción. Itzulpena, Jem Cabanes. Bartzelona: Península

Pallasmaa, Juhani. (1996) 2006. Los ojos de la piel: La arquitectura y los sentidos. Itzulpena, Moisés Fuente. Bartzelona: Gustavo Gili

— . 2018. Esencias. Itzulpena, Carles Muro. Bartzelona: Gustavo Gili

Sennett, Richard. (1997) 2009. El artesano. Itzulpena, Marco Aurelio Galmarini. Bartzelona: Anagrama

Smithson, Alison \& Peter Smithson. 1973. Without rhetoric: An architectural aesthetic; 1955 1972. London: Latimer New Dimensions

Zumthor, Peter. (1998) 2014. Pensar la arquitectura. Itzulpena, Pedro Madrigal. Bartzelona: Gustavo Gili 


\section{Oharrak}

${ }_{1}^{1}$ Artikulu hau Euskal Unibertsitate Sisteman Ikerketa Talde Egonkortua den eta Eusko Jaurlaritzak diruz laguntzen duen ikerketa taldearen (GIC-GV-IT1096-16) testuinguruan idatzi da. Baita MINECO eta Europako FEDER-ek (I+D+i) diruz lagundutako "El arte y las transformaciones del espacio común del territorio. [Sostenibilidad estética en canteras de corte y bordes de agua]" (HAR2016-78241-P) proiektuaren baitan ere

${ }^{2}$ Euskaltzaindiaren Hiztegian "lekutu” hitzak urrundu, baztertu, desagertu esan nahi du. Testu honetan, aldiz, leku bihurtu bezala erabili da.

${ }^{3}$ Simon Smithson, Alison eta Peter Smithson arkitektoen semearekin, Londresen lan egiten duen arkitektura estudioan, 2020ko otsailaren 18an izandako solasalditik hartua.

${ }^{4}$ Richard Serra: 'To lift' (1967). eskuragarri The Museum of Modern Art (MOMA) weborrian: https://www.moma.org/audio/playlist/1/8

${ }^{5}$ Richard Serra: 'Verblist' (1967-68), eskuragarri The Museum of Modern Art (MOMA) web-orrian: https://www.moma.org/collection/works/152793 